\title{
HEAT WAVES FREQUENCY. A STUDY CASE OF IASI CITY, ROMANIA (1961-2016)
}

\author{
Roxana Simona BOCANCEA ${ }^{1,2}$
}

DOI: 10.21163/GT_2018.131.02

\begin{abstract}
:
Among the weather events generated by extreme temperatures, heat waves are some of the most harmful which in the recent years has obviously increased the nature of climate risk. The main reason why we decided to conduct such a research is due to the profound socioeconomic impact of heat waves in urban areas. The aims of this study were to analyze heat waves at Iasi meteorological station based on the daily maximum temperature during 56year period (1961-2016). The frequency and duration were analyzed by applying the $95^{\text {th }}$ percentile method and choosing the length of an event of minimum three consecutive days. The results were showing that the most frequent heat waves are those lasting 3 and 4 days, but regarding the duration, the longest heat waves were considered during the summer of 2007, lasting 10 days at Iasi meteorological station. The main result is that the frequency trend is significantly increasing.
\end{abstract}

Key-words: Heat waves, Climate change, Iasi Muncipality, Percentile $95^{\text {th }}$

\section{INTRODUCTION}

In the last two decades many climate change studies have focused on extreme temperatures as they have significant impact on environment and society. One of the most harmful weather events generated by extreme temperatures are heat waves (HWs). Heat waves have discernible impacts including rise in mortality and morbidity (Knowlton et al., 2009; Bassil et al., 2007), an increased strain on infrastructure (power generation, water supply, transportation) (et al., 2003) and consequent impacts on society.

The socio-economic impact of heat waves has maintained the interest of scientists in this subject who has undertaken it in various ways. In Romania many studies of heat waves were conducted developed at regional or local scale. Some of the studies focus on the impacts and response to heat waves and some of the studies focus on the cause of the heat waves. In a recent research one, carried out by Sfica et al., 2017 were analyzed the synoptic conditions which generate heat waves and warm spells in Romania. The authors found two major conditions responsible of the heat waves, one being radiative type, respectively advective type. Another study focus on some of the important indices of the heat waves in Romania, such as amplitude, magnitude, number of events, duration and frequency which shows that most of the indices have statistically significant increasing trends (Croitoru et al., 2016).

For instance, in Romania the results of certain studies indicated changes in the extremes air temperature, pointing out their correlation with changes of large-scale circulation patterns. The connection between heat waves and large-scale circulation in southeastern Europe was investigated by Spinoni et al., 2010; Georgescu et al., 2013.

\footnotetext{
${ }^{1}$ Alexandru Ioan Cuza University, 700505 Iasi, Romania

${ }^{2}$ Université de Lorraine, Laboratoire LOTERR-EA7304, 57045 Metz Cedex 01, France, roxana.bocancea@univ-lorraine.fr
} 

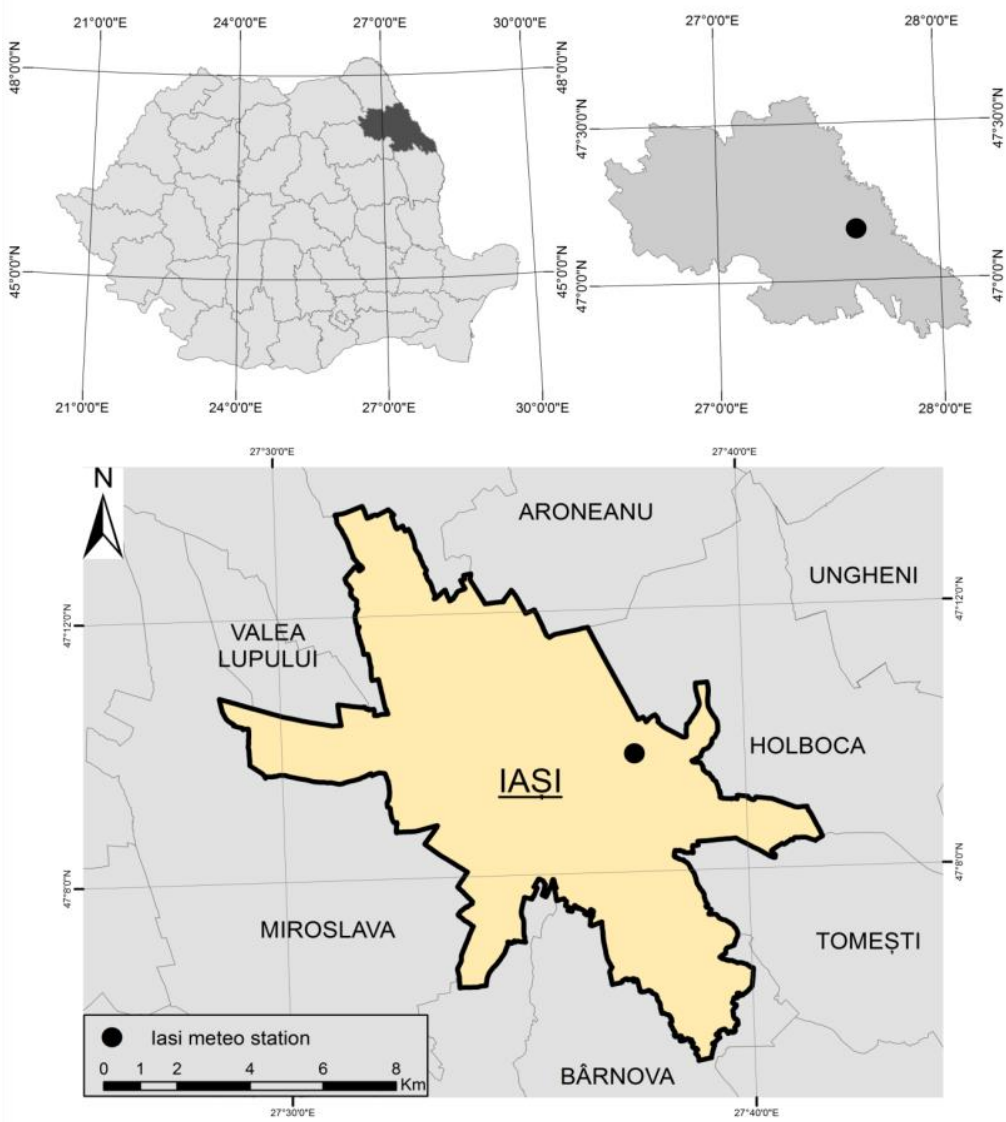

Fig 1. Location of the study area

The consequences of the heat waves are not always related to the hazard itself but also to the characteristics of the population in the affected areas. Therefore, are expected that heat waves will have more severe impact on vulnerable population groups as those with pre-existing health problems, socially isolated elderly people, homeless people, young children, people suffering from obesity and chronic diseases, also those with a low socioeconomic status (Mattchies et al., 2008). The impacts of heat waves in Europe have increased the mortality in most of the main cities, due to the sensitivity of the population to high temperatures, as well as their ability to cope with heat exposure (Wilhelmi and Hayden, 2010). Most of the impact of a heat wave depends also on the frequency of high temperature over a longer time period, on the time of the year that they occur and also as an indirect consequence on the population are the influences of other phenomena such as slope instabilities and floods (IPCC, 2012). The most significant heat wave events that have affected European countries in the last decades being recorded within the EM-DAT database are listed in the Table 1. 
Table 1.

The most significant heat waves events in Europe since 2003 (EM-DAT)

\begin{tabular}{|l|l|l|}
\hline Most affected countries & Date & Number of victims \\
\hline Russia & June 2010 & 55,736 \\
Italy & July 2003 & 20,089 \\
France & August 2003 & 19,490 \\
Spain & August 2003 & 15,090 \\
Germany & August 2003 & 9355 \\
Portugal & August 2003 & 2696 \\
France & July 2006 & 1388 \\
\hline
\end{tabular}

\section{DATA}

For this study case we used the maximum daytime from Iasi weather station located in the urban area of Iasi municipality. The meteorological station used in this work reflects both urban and suburban conditions. The analysis is based on the maximum daytime air temperatures data series available for Iasi weather station in Romania, obtained from the ECA\&D project database, which covers continuous measurements over a period of 55 years (1961-2016) (http://eca.knmi.nl/), and Meteomanz data base (http://www.meteomanz.com).

\section{METHODOLOGY}

Heat waves can be defined in various ways and detection methods. There are many definitions and some of them may be very ambiguous, but almost all of the definitions consider a threshold and a minimum number of consecutive days when the specific threshold is exceeded. One way to define heat waves is based on the concept of establishing specific thresholds by analyzing the persistence and frequency of heat waves. Another definition, of World Meteorological Organization is "when the daily maximum temperature in more than five consecutive days exceeds the average maximum number of consecutive days (larger than 5) during which the maximum temperature surpasses the average over 1961-1990 with at least 5 degrees.

In order to evaluate the heat waves risks, it's recommended to take into consideration both the probability of occurrence of the phenomenon and its consequences. However, because is very difficult to focus on the consequences because it requires a considerable amount of detailed data which are not available due to privacy and data protection reasons, in the current study case we aimed to detect and analyze the frequency and duration of the heat waves for the past decades in the metropolitan area of Iasi city, based on daily observation data over the period 1961 -2016 and to continues with another research in order to study the amplitude and magnitude.

For this study case we used the maximum daytime from Iasi weather station located in the urban area of Iasi municipality. The meteorological station used in this work reflects both urban and suburban conditions. Data processing was performed by the method of 
percentiles, provided by Microsoft Excel software through the pre-defined functions PERCENTILE. We applied the method of $95^{\text {th }}$ percentile as it allows detection of the heat waves all around the year and under each weather station without location and season problem (Perkins \& Alexander, 2013; Croitoru, 2014).

In the first stage, the method involves choosing a benchmark, in our case $95^{\text {th }}$ percentile, and placing percentile function, in the formula bar of the program, and highlighting the probability of occurrence of the phenomenon of $95 \%$. The identification, of exceeded percentile was achieved by using a comparison function that indicates whether through one annual value was exceeded and zero if no value was exceeded. In the second stage using a macro command, the maximum temperature values were extracted for the exceed situations as percentile values. To study the frequency of massive heating phases were used only periods longer than three consecutive days witch exceed the percentile value.

Table 2.

Model to calculate the daily percentile

\begin{tabular}{|c|c|c|c|c|c|c|c|c|}
\hline & 1961 & 1962 & 1963 & 1964 & $\begin{array}{l}\cdots \ldots \\
\ldots\end{array}$ & 2015 & 2016 & \begin{tabular}{|l|} 
95th \\
Percentile
\end{tabular} \\
\hline & \multicolumn{8}{|c|}{ Maximum temperature (OC) } \\
\hline January, 1 & 3 & 2 & -4 & 2 & ...... & 1 & -6.1 & 7.77 \\
\hline January, 2 & 1.5 & 2.2 & -1.2 & -1.6 & ..... & 5.9 & -8.5 & 8.62 \\
\hline January, 3 & 6 & 2 & -2.9 & 1.7 & $\ldots \ldots$ & 6.1 & -11.1 & 6.90 \\
\hline .............. & a.... & $\ldots \ldots$ & $\ldots \ldots$. & ....... & .... & 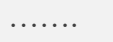 & n.......... & n......... \\
\hline July, 1 & 24.6 & 24 & 32.4 & 17 & $\ldots \ldots$ & 28.8 & 32.5 & 32.42 \\
\hline July, 2 & 28.4 & 24.1 & 27.8 & 18.9 & $\ldots \ldots$ & 26.3 & 32.3 & 33.1 \\
\hline$\cdots$ & ‥ & $\cdots$ & & & .... & & $\cdots$ & \\
\hline December, 29 & 1.2 & -5.6 & 2.2 & 11 & $\begin{array}{l}\cdots \cdots \\
\ldots\end{array}$ & 0.8 & 1.9 & 11.15 \\
\hline December, 30 & 2 & 5.5 & 1.5 & 6.5 & $\begin{array}{l}\cdots \cdots \\
\ldots\end{array}$ & -1 & -0.3 & 12.12 \\
\hline December, 31 & 2.2 & 0.8 & -1 & 1.6 & $\begin{array}{l}\cdots \cdots \\
\ldots\end{array}$ & -2.1 & 3.1 & 9.57 \\
\hline
\end{tabular}

For the next stage, we created the frequency graphs through which evolution in time and space was highlighted. Below, is presented an example of a model of detecting heat waves (Table 3). 
Table 3.

Model of detecting a heat wave based on the $95^{\text {th }}$ percentile method at Iasi Weather Station

\begin{tabular}{|r|r|r|r|r|}
\hline Data in the range & Maximum temperature & Test * & 95th percentile value & \multicolumn{2}{|c|}{ Heat waves } \\
\hline 14.07 .2007 & 28,2 & 0 & 33,27 & No \\
\hline 15.07 .2007 & 30,9 & 0 & 33,97 & No \\
\hline 16.7 .2007 & 35,2 & 1 & 33,85 & Yes \\
\hline 17.7 .2007 & 37 & 1 & 34,95 & Yes \\
\hline 18.7 .2007 & 38,3 & 1 & 34,9 & Yes \\
\hline 19.7 .2007 & 39,8 & 1 & 34,87 & Yes \\
\hline 20.7 .2007 & 39,8 & 1 & 34,73 & Yes \\
\hline 21.7 .2007 & 39,7 & 1 & 33,82 & Yes \\
\hline 22.7 .2007 & 40,1 & 1 & 33,77 & Yes \\
\hline 23.7 .2007 & 34,3 & 1 & 33,88 & Yes \\
\hline
\end{tabular}

\section{RESULTS AND DISCUSSION}

This type of analysis of daytime temperature data series recorded between 1961-2016 for Iasi weather station in Romania highlighted that during this time 1118 days with heat waves were found and a total of 98 heat waves of various lengths. The production of heat waves that exceed 10 days is exceptional. Such exceptions have a very low frequency of occurrence between 1961 and 2016. Regarding the duration of the heat waves, the most frequent are those between 3 and 5 days (Fig. 2). Those longer than three days are the most frequent, as expected and have a relative frequency of $41.7 \%$. They are followed by heat waves 4-days long (35.4\%), 5-days long (11.5\%) and 8-days long (5.2\%).

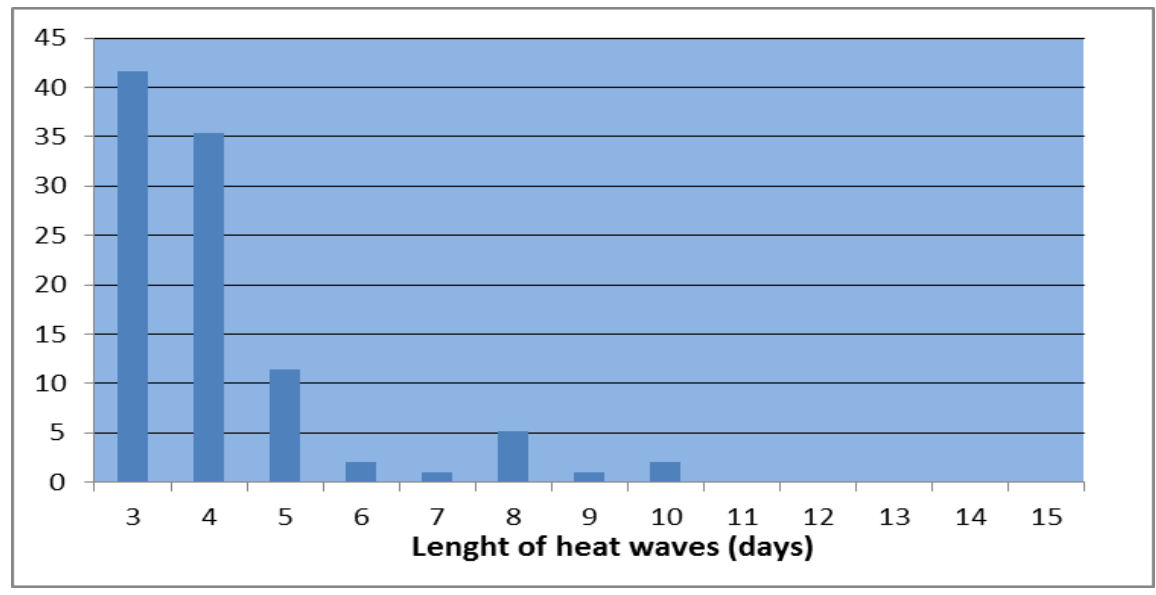

Fig. 2. Relative frequency (\%) of heat waves period in Iasi (1961-2016) 
The two longest intervals of heat waves were recorded both in 2007, between 20th and 29th of May and 16th and 25th of July, when the average of maximum temperature in Iasi was $32.79{ }^{\circ} \mathrm{C}$ and $37.82{ }^{\circ} \mathrm{C}$ (Fig. 3 and Fig. 4).

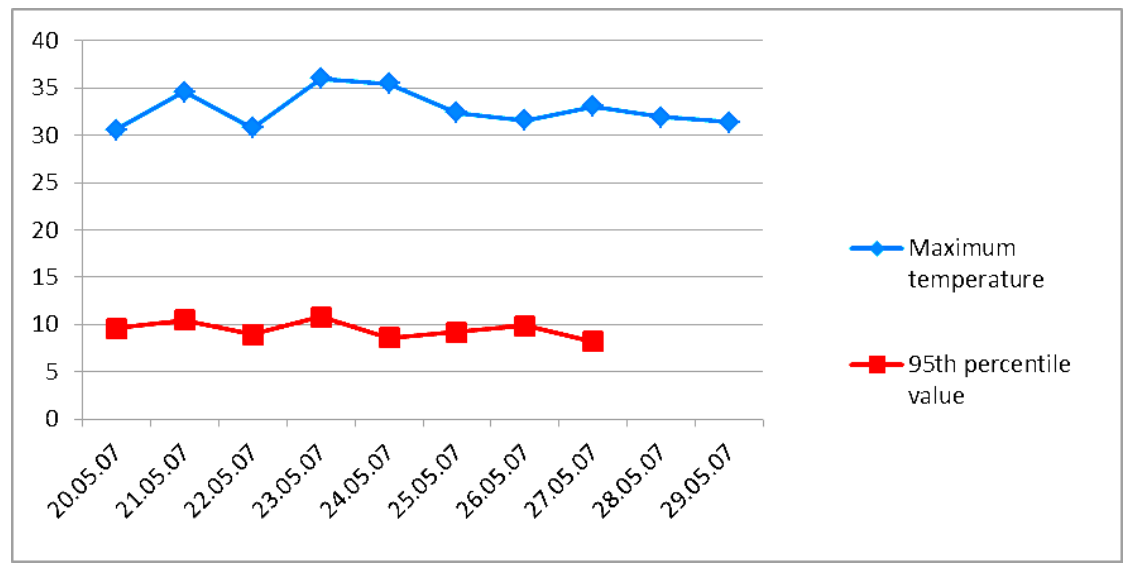

Fig. 3. Maximum temperature during one of the longest heat wave in Iasi, between 1961-2016

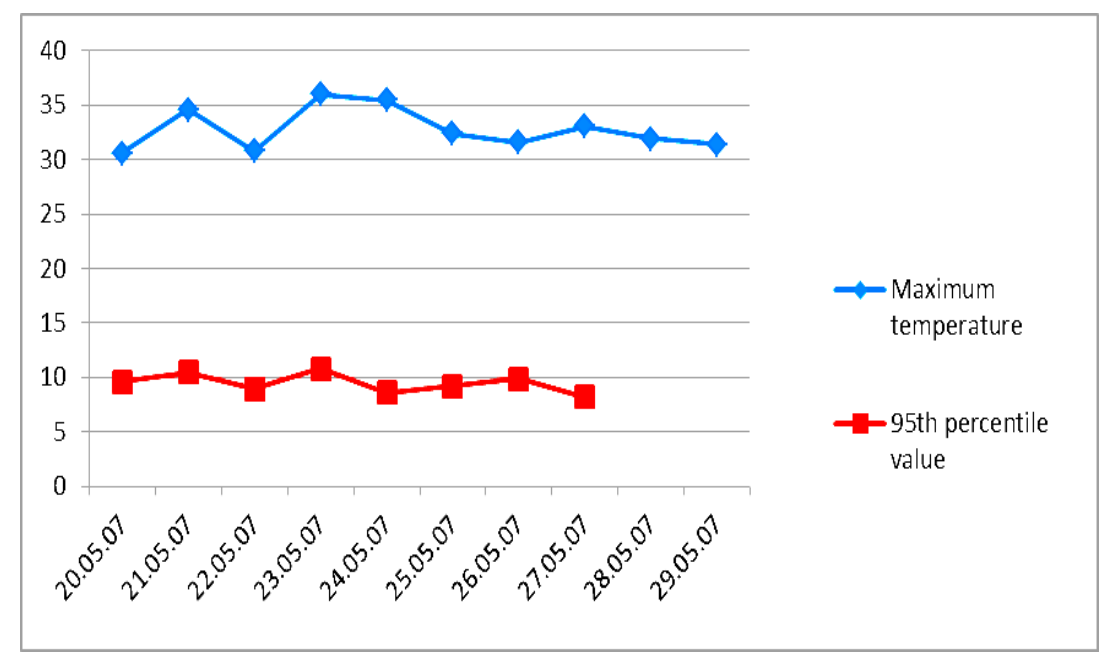

Fig. 4. Maximum temperature during one of the longest wave in Iasi, between 1961-2016.

Responsible for this is the severe heat wave which affected a large portion of Russia (western and central parts), as well the southeastern Europe during May, June-July (WMO, 2007). The maximum temperature measured during this interval was $36^{\circ} \mathrm{C}$ and $40.1^{\circ} \mathrm{C}$.

One of the most important idicators of the heat waves reprezents the annual evolution. The graph shows an significant increasing trend of heat waves (Fig.5). During the last decade the number of 6 heat waves occurred, summer being the season with the most frequent heat waves. 


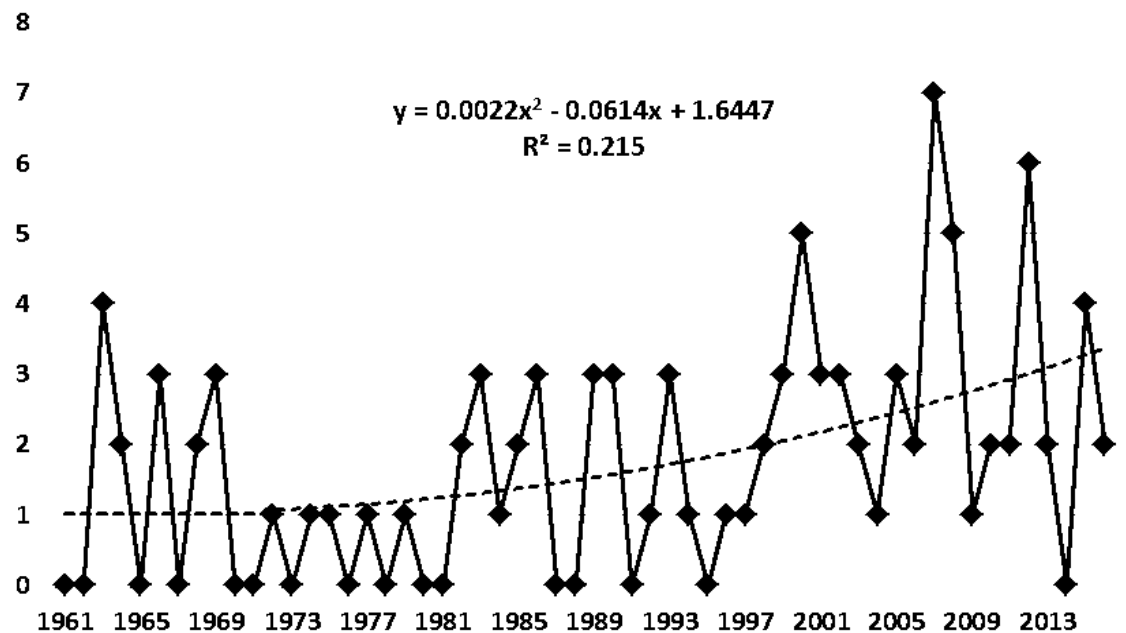

Fig. 5. The annual evolution of heat waves in Iasi municipality between 1961-2016

But the mere exploratory analysis of this series does not allow us to accept the growing parabolic trend just as easily. Even visually, there is a difference between growing and declining periods. That's why we applied the Haidu \& Magyai-Saska (2009) method that make it possible to detect the sequential trend signal.

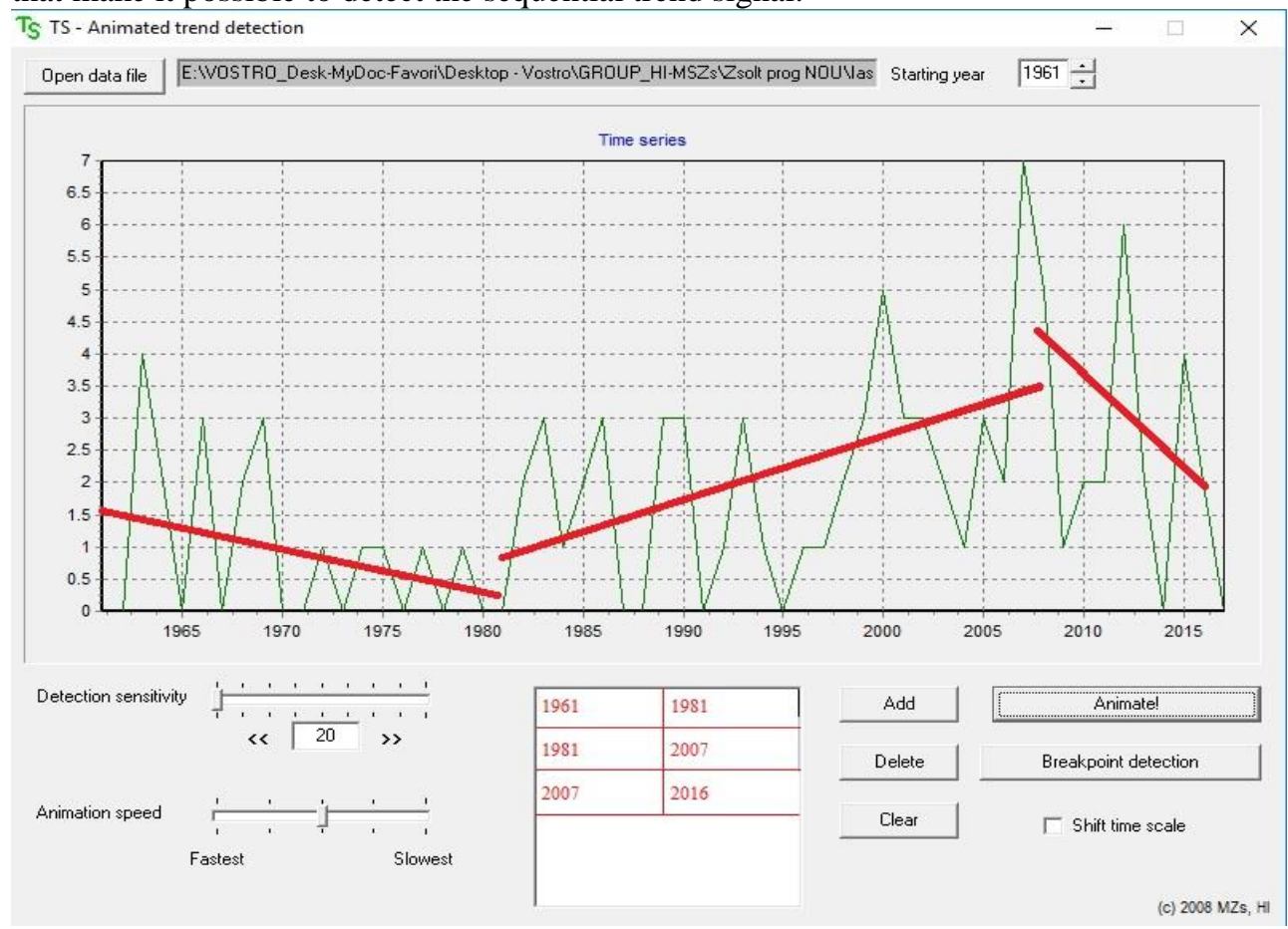

Fig. 6. Sequential trend signal detection (the method of Haidu \& Magyari-Saska, 2009). 
This investigation seems contrary to almost unanimous views of today that seek arguments of global warming but which actually support the idea of carefully examining the properties of time series (Haidu, 2016).

The result shows that the trend during 1961-2016 in Fig. 5, does not increase without limit, as would alarm the current theory of global climate change. The graph (Fig. 6) shows that after the year 2008 the number of annual waves tends to decrease, which does not, however, lead to the conclusion that in the future there could be no further increases or alternatives of opposite sequences.

Because our study has as its object the frequency analysis, obviously we need to call for more sophisticated methods suitable for the study of extremities. In hydrology, for example, the analysis of flash floods (the same several consecutive days of extreme values), can not be conceived without frequency analysis and probability computations (Györi et al., 2016). I have studied which of the specific statistical distributions for extreme data would be most suitable for the series of heat wave. Of course, we must first remove the global trend in order to achieve a residual stationary series. The processing of the time series, however, was not enough because the residual series had negative values. Therefore, we had to use a transformation of the residual series; the most suitable was the "absolute value" transform.

Good candidates were GEV, Gamma and Weibull, all three passed the $\chi^{2}$ test. But the most appropriate, on the base of Bayesian information criterion and Akaike information criterion seems to be the Weibull distribution (Fig. 7).

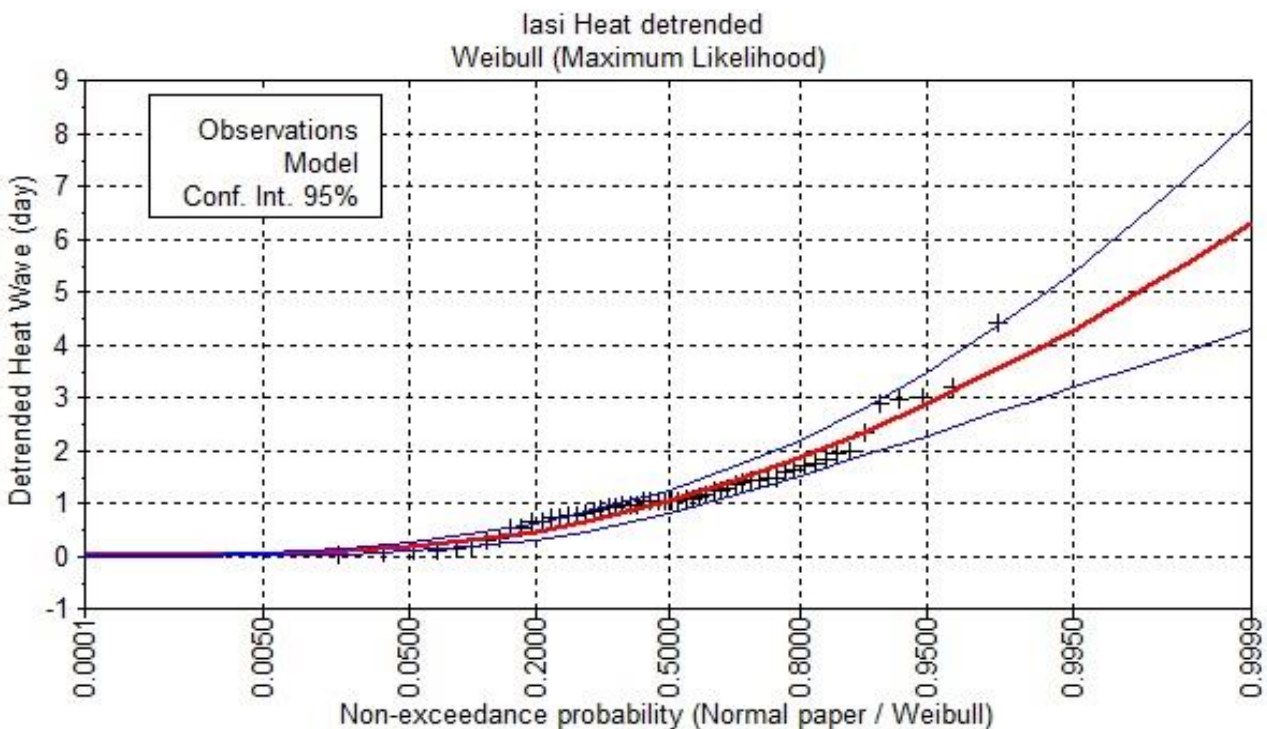

In this case, for a return period $\mathrm{T}=100$ the quintile $\mathrm{XT}=3.87$ days and for $\mathrm{T}=1000$, $\mathrm{XT}=5.14$. It should be noted that the above results are specific for the residual series, ie no global trend. In the hypothesis that the global trend remains in the future, we should add another 3 days to the results, and the consequences would be: $\mathrm{XT}_{100}=7$ days of heat wave, $\mathrm{XT}_{1000}=8$ days of heat wave. And if the global trend persists for the next decade then, around the year 2025, the crisis it would be even bigger because the results would have to be added for 1.5-2 days. 


\section{CONCLUSIONS}

In our study changes in heat waves were analyzed over a period of 56-year (1961 2017). We have applied percentile-based method $\left(95^{\text {th }}\right)$ on an amount of data and were calculated for each day of the year, from $1^{\text {st }}$ of December to $31^{\text {st }}$ of December. Based on our analysis we can conclude that most the most frequent heat waves are those lasting 3 and 4 days, but regarding the duration, the longest heat waves were considered during the summer of 2007, lasting 10 days, at Iasi meteorological station. From the first decade of the XXI century we can notice an increase in the annual frequency of the heat waves, due to the global warming and climate change.

As a consequence of increasing heat waves phenomena are the negative impact on economic activity, human health, the ecosystems, and infrastructure which put us in the situation to implement different strategies and emergency plans to reduce the impact. We consider that in the study must be done in the future, at a larger scale and vulnerability of different sectors must be studied, and also an amount of different variable of heat waves as magnitude and amplitude in order to conclude the real causes and impact.

\section{R E F E R E N C E S}

Bassil, K., D. C. Cole, K. Smoyer-Tomic, and M. Callaghan. 2007. What is the Evidence on Applicability and Effectiveness of Public Health Interventions in Reducing Morbidity and Mortality during Heat Episodes? Vancouver, BC: National Collaborating Centre for Environmental Health.

Croitoru, A.-E. (2014) Heat waves. Concept, definition and methods used to detect. Riscuri și Catastrofe, 15(2), 25-32.

Croitoru, A.-E.; Piticar, A.; Ciupertea, A.F.; Roşca, C.F. (2016) Changes in heat waves indices in Romania over the period 1961-2015. Glob. Planet. Change, 146, 109-121

ECA\&D, http://eca.knmi.nl/

Georgescu F., Andrei S., Stefan S., Stefanescu V., Barbu N. (2013) Heat waves in south-eastern Europe - identification of synoptic patterns using COST733 Catalogues. Geophysical Research Abstract, 15:EGU2013-11834.

Győri M-M., Haidu I., Humbert J., (2016) Deriving the floodplain in rural areas for high exceedance probability having limited data source. Environmental Engineering and Management Journal, 15, (8), 1879-1887.

Haidu I., Magyari-Saska Z. (2009) Animated Sequential Trend Signal Detection in Finite Samples. Proceedings of the ITI 2009 31st Int. Conf. on Information Technology Interfaces, June 22-25, 2009, Cavtat, Croatia. Edited by: LuzarStiffler, V; Jarec, I; Bekic, Z. 249-254.

Haidu, I. (2016). What Is Technical Geography. Geographia Technica, 11(1), 1-5. DOI: 10.21163/GT_2016.111.01 
Knowlton, K., M. Rotkin-Ellman, G. King, H. G. Margolis, D. Smith, G. Solomon, R. Trent, and P. English (2009), The 2006 California heat wave: Impacts on hospitalizations and emergency department visits. Environ. Health Perspect., 117, 61-67.

Meteomanz, http://www.meteomanz.com

Perkins, S.E., Alexander, L.V., 2013. On the measurement of heat waves. J. Clim. 26, 4500-4517. http://dx.doi.org/10.1175/JCLI-D-12-00383.1.

Sfîcă L., Croitoru A-E., Iordache I., Ciupertea A-F. (2017) Synoptic Conditions Generating Heat Waves and Warm Spells in Romania. Atmosphere, 8, 50; doi:10.3390/atmos8030050.

Spinoni, J.; Lakatos, M.; Szentimrey, T.; Bihari, Z.; Szalai, S.; Vogt, J.; Antofie, T. (2015) Heat and cold waves trends in Carpathian Region from 1961 to 2010. Int. J. Climatol, 35, $4197-$ 4209.

Smoyer-Tomic K.S., Kuhn R., Hudson A. (2003) Heat Wave Hazards: An Overview of Heat Wave Impacts in Canada. Natural Hazards, 28(2-3), 463-485.

Wilhelmi O.V., Hayden M.H. (2010) Connecting people and place: a new framework for reducing urban vulnerability to extreme heat. Environ. Res. Lett. 5, DOI: 10.1088/17489326/5/1/014021. 